OPEN ACCESS

Edited by:

Richard Lamont,

University of Louisville, United States

Reviewed by:

Pirkko Pussinen,

University of Helsinki, Finland

*Correspondence:

Hiroki Takeuch

takeuchih@dent.osaka-u.ac.jp

Specialty section: This article was submitted to Oral Infections and Microbes, a section of the journal

Frontiers in Oral Health

Received: 29 December 2021

Accepted: 14 January 2022

Published: 08 February 2022

Citation:

Takeuchi H, Nakamura E, Yamaga S and Amano A (2022) Porphyromonas

gingivalis Infection Induces

Lipopolysaccharide and Peptidoglycan Penetration Through Gingival Epithelium

Front. Oral. Health 3:845002.

doi: 10.3389/froh.2022.845002

\section{Porphyromonas gingivalis Infection Induces Lipopolysaccharide and Peptidoglycan Penetration Through Gingival Epithelium}

\author{
Hiroki Takeuchi ${ }^{1 *}$, Eriko Nakamura ${ }^{2}$, Shunsuke Yamaga ${ }^{2}$ and Atsuo Amano ${ }^{2}$ \\ ${ }^{1}$ Department of Preventive Dentistry, Osaka University Dental Hospital, Suita, Japan, ${ }^{2}$ Department of Preventive Dentistry, \\ Graduate School of Dentistry, Osaka University, Suita, Japan
}

Periodontal diseases initiate on epithelial surfaces of the subgingival compartment, while the gingival epithelium functions as an epithelial barrier against microbial infection and orchestrates immune responses. Porphyromonas gingivalis is a major pathogen of periodontal diseases and has an ability to penetrate the epithelial barrier. To assess the molecular basis of gingival epithelial barrier dysfunction associated with $P$. gingivalis, we newly developed a three-dimensional multilayered tissue model of gingival epithelium with gene manipulation. Using this novel approach, P. gingivalis gingipains including Argor Lys-specific cysteine proteases were found to specifically degrade junctional adhesion molecule 1 and coxsackievirus and adenovirus receptor in the tissue model, leading to increased permeability for lipopolysaccharide, peptidoglycan, and gingipains. This review summarizes the strategy used by $P$. gingivalis to disable the epithelial barrier by disrupting specific junctional adhesion molecules.

\section{Keywords: periodontitis, Porphyromonas gingivalis, gingipains, gingival epithelium, lipopolysaccharide, peptidoglycan, epithelial barrier, tissue model \\ SIGNIFICANCE OF PORPHYROMONAS GINGIVALIS INFECTION IN HUMAN GINGIVAL EPITHELIUM}

Epithelial cells are located on the front line of infection defense, and function as a physical barrier against pathogenic bacteria and their products. The epithelial barrier is formed by cell-cell adhesion, and consists of tight junctions that prevent leakage of transported substances, and seal the paracellular pathway. Human gingival epithelial cells have been reported to express tight-junction associated proteins, such as claudin, occludin, junctional adhesion molecule 1 (JAM1), and zonula occludens-1 [1], among which JAM1, an immunoglobulin superfamily protein, reportedly localizes in mucosal epithelium of numerous organs [2].

Periodontitis is basically an infectious disease that causes destruction of periodontal tissues by interactions between periodontal pathogens and host cells [3]. Since gingival epithelial cells are the first to face periodontal pathogens, gingival epithelial tissues are potentially involved in the pathogenesis and progress of periodontitis. Porphyromonas gingivalis, a Gram-negative anaerobe, is a periodontal pathogen that expresses a variety of virulence factors, such as lipopolysaccharide (LPS), peptidoglycan (PGN), and gingipains. Periodontal diseases are multispecies infections involving pathogenic communities in which $P$. gingivalis can increase the pathogenicity of the entire multispecies periodontal community [3]. 
Various studies have shown that $P$. gingivalis occurrence is significantly associated with initiation of periodontitis, with odds ratios of 11.788 [4], 12.3 [5], and 5.6 [6] reported. It is also known that an increase in amount of "red complex" species, consisting of P. gingivalis, Treponema denticola, and Tannerella forsythia, in subgingival biofilm is related to initiation and progression of periodontitis [7]. A cross-sectional study revealed that $P$. gingivalis is the most influential pathogen among red complex bacteria [8]. However, it is ethically difficult to analyze the effects of $P$. gingivalis infection on tight junction-associated proteins using human gingival epithelium specimens. Hence, features of the physiological function related to tight junction-associated proteins in the oral cavity have become an interesting focus of research.

\section{ADVANTAGES OF 3D-TISSUE MODELS OF HUMAN GINGIVAL EPITHELIUM}

From the standpoint of replacement, reduction, and refinement (3Rs), alternative methods for animal experiments are needed for medical research studies [9]. Physiological tissues are composed of various types of cells and connective tissues, thus how to construct three-tissue models with similar functions in living tissues has been investigated. Within an organism, the extracellular matrix has an important role to regulate the interface-surface structure of host cells. We previously reported that a cell-accumulation technique [10] using fibronectin and gelatin, extracellular matrixes, was useful to re-construct human gingival epithelial tissues [11, 12]. The advantages of this technique include (1) development of healthy human tissues, (2) gene manipulation including overexpression and knockdown, (3) direct measurement of fluorescent-tracer transmission in human tissues, (4) time-course observations of pathological condition before disease onset, and (5) administration of LPS and PGN, for examining PAMPs and infection by $P$. gingivalis. We have found that $3 \mathrm{D}$-tissue models of gingival epithelium are useful for defining the cause-and-effect relationships of risk factors in terms of elimination of potential confounding factors.

\section{P. GINGIVALIS GINGIPAINS DEGRADE JAM1 AND CXADR}

P. gingivalis secretes Arg- and Lys-specific cysteine proteases, termed Arg-gingipains (RgpA and $\mathrm{RgpB}$ ) and Lys-gingipain (Kgp), respectively, which are major virulence factors [13, 14]. In a previous study, to clarify which tight junction-associated protein(s) are degraded by $P$. gingivalis infection, we infected immortalized human gingival epithelial (IHGE) cells [15] with $P$. gingivlis ATCC 33277 or KDP136, a $\Delta k g p \Delta r g p A \Delta r g p B$ mutant [16], for $1 \mathrm{~h}$. Immunoblot and confocal microscopic analyses revealed that $P$. gingivalis apparently degraded JAM1 and coxsackievirus and adenovirus receptor (CXADR), another JAMfamily protein [17], but not claudin 1, claudin 4, E-cadherin, occludin, or zonula occludens-1, in a gingipains-dependent manner $[11,12]$. Notably, medium used for culturing $P$. gingivalis WT, but not that used for a $\Delta \operatorname{kgp} \Delta \operatorname{rgp} A \Delta r g p B$ mutant, also degraded JAM1 and CXADR of IHGE cells, indicating that gingipains function to degrade JAM1 and CXADR.

\section{SPECIFIC DEGRADATION OF JAM1 AND CXADR BY GINGIPAINS}

JAM family proteins have an extracellular domain along with two immunoglobulin-like domains, a single transmembrane domain, and a short cytoplasmic tail with a PDZ-domain-binding motif [18]. Hence, we constructed chimeric proteins of JAM1 and CXADR expressed by IHGE cells, and infected cells with $P$. gingivalis, after which the responsible residues of JAM1 K134 and R234, and CXADR R145 and K235 were examined for determining gingipains degradation (Figure 1). JAM1 K134 and CXADR R145 are located between the two immunoglobulin domains, while JAM1 R234 and CXADR K235 are set at the Nterminus of the transmembrane domain. A dimerization motif in the N-terminal immunoglobulin domain is essential for JAM1or CXADR-homodimer formation, thus gingipains efficiently dampen the functions of JAM1 and CXADR.

Fusobacterium nucleatum and Streptococcus gordonii are human oral bacteria that can assemble mixed-species communities [19]. Hence, IHGE cells were infected with $F$. nucleatum or S. gordonii, and it was confirmed that the protein levels of JAM1 and CXADR were not decreased, thus indicating that F. nucleatum and S. gordonii do not degrade JAM1 and CXADR $[11,12]$.

Next, 3D-tissue models of gingival epithelium were constructed, and localization of JAM1 and CXADR was confirmed and found to be comparable to that seen in human gingiva. We also found that $P$. gingivalis WT decreased JAM1 and CXADR even in tissues 3-4 layers below the surface, whereas the $\Delta k g p \Delta r g p A \Delta r g p B$ mutant did not $[11,12]$. These results indicate that gingipains continuously degrade JAM1 and CXADR, and deeply invade human gingival epithelial tissues.

\section{P. GINGIVALIS INDUCES PENETRATION OF LPS AND PGN THROUGH GINGIVAL EPITHELIUM}

LPS, a gram-negative bacteria endotoxin, and PGN, which exists in a mesh-like pattern outside the plasma membrane of most bacteria, are known as pathogen-associated molecular patterns (PAMPs) that cause initiation of host immune response [20]. In cases with leukocyte adhesion deficiency, one of the syndromes associated with periodontitis [21], LPS in the subepithelial area was reported to be detected in gingival tissues, but not in those from healthy cases [22]. In addition, plasma LPS levels were found to be correlated with multiple clinical parameters of aggressive periodontitis [23] and decreased by periodontal therapy [24]. Hence, we hypothesized that PAMPs from oral bacteria penetrate gingival epithelial tissues.

To assess the contribution of JAM1 expression to the permeability of gingival epithelial cells, 3D-tissue models of gingival epithelium were generated, then permeability assays were performed using fluorescent probe-tagged LPS or PGN 


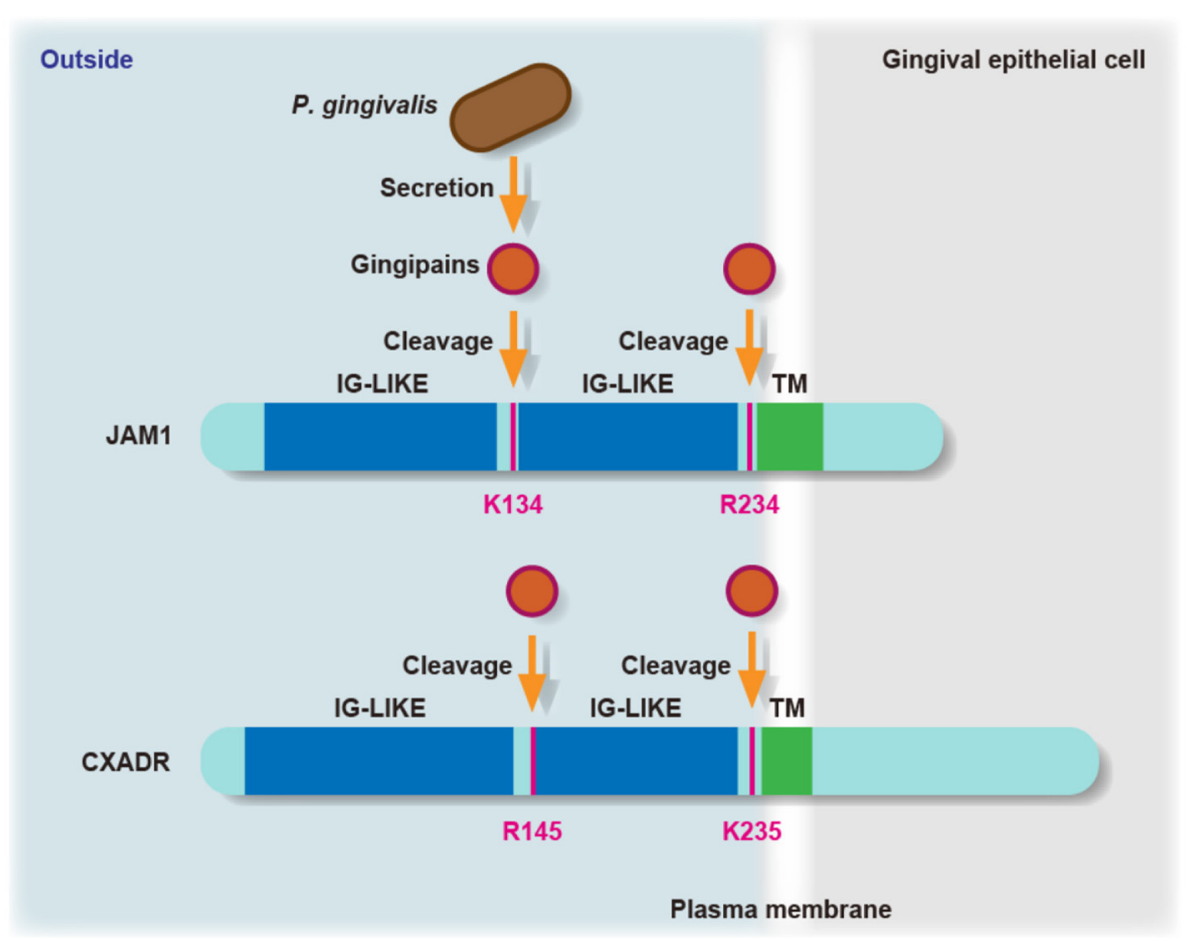

FIGURE 1 | The residues involved in degradation of JAM1 and CXADR by $P$. gingivalis gingipains. Schematic view of the JAM1 and CXADR structure in gingival epithelial cells. The K134 and R234 residues of JAM1, and the R145 and K235 residues of CXADR are involved in degradation by $P$. gingivalis gingipains in gingival epithelial cells. IG-LIKE, immunoglobulin-like domain (blue); TM, transmembrane domain (green).

in combination with $P$. gingival infection. To confirm the involvement of JAM1 or CXADR in $P$. gingivalis-affected permeability, 3D tissues were infected with $P$. gingivalis using IHGE cells overexpressing JAM1 or CXADR, which were then treated with fluorescent tracers [11, 12]. Thirty minutes after administration, the permeability to LPS or PGN was increased by $P$. gingivalis infection, whereas that was decreased by JAM1 or CXADR overexpression in gingival epithelial tissues. These results suggest that JAM1 and CXADR degradation by $P$. gingivalis causes penetration of gingival epithelium by LPS and PGN (Figure 2).

\section{DISCUSSION}

\section{Difference Between Gene Expression and Protein Localization}

We confirmed that the immature forms of JAM1 and CXADR possessed a signal peptide and were localized in the endoplasmic reticulum $[11,12]$. Generally, the levels of the immature forms of JAM1 and CXADR are proportional to those of the messenger RNA levels. In contrast, $P$. gingivalis degraded mature forms of JAM1 and CXADR in the plasma membrane, but not the immature forms in IHGE cells. These results suggest that surface protein localization of JAM1 and CXADR is needed to be confirmed in gingival epithelial cells to accurately evaluate the effects of risk factors of periodontitis.

\section{Protein Modification}

It has been reported that JAM1 is phosphorylated at Y280 [25] and S284 [26], and glycosylated at N185 [27], while CXADR is glycosylated at N106 and N201 [28]. In general, protein phosphorylation modulates subcellular localization, and $\mathrm{N}$-linked protein glycosylation is involved in cell-cell and cell-extracellular matrix attachment. Hence, elucidation of risk factors of periodontitis that have effects on JAM1- or CXADRprotein modification is considered to helpful to better understand its etiology.

\section{Intracellular Trafficking}

The C-terminal cytosolic domain of JAM1 possesses a class II PDZ domain binding motif (-SFLV-COOH) [29]. In cytosolic space, JAM1 is known to associate with various partner proteins via the PDZ domain [30]. We confirmed that the immature forms of JAM1 and CXADR were localized in the endoplasmic reticulum, in which these proteins were apparently digested as a single peptide and $\mathrm{N}$-glycosylated for maturation. To show biological activity, JAM family proteins must be transferred from the endoplasmic reticulum to plasma membrane, in which case regulator proteins may also bind with JAM via the PDZ domain. We recently observed that JAM1 localization in the plasma membrane was not disturbed by actin polymerization inhibitors (unpublished data). In contrast, actin depolymerization has been shown to disturb plasma-membrane localization of claudin-1 and occludin, tight junction proteins [31]. Thus, it is considered that 


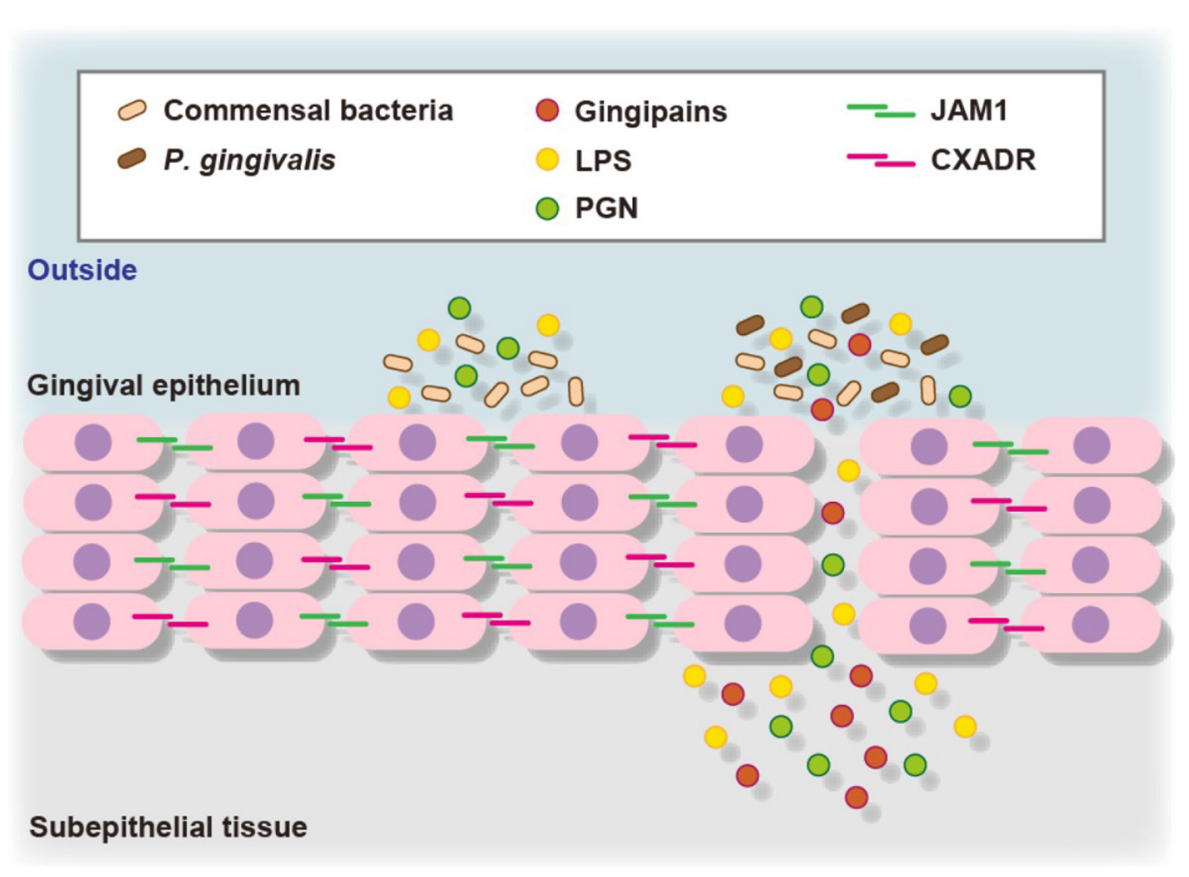

FIGURE 2 | Proposed model of transfer of bacterial virulence factors by $P$. gingivalis gingipains through gingival epithelium. $P$. gingivalis gingipains degrade JAM1 and CXADR, leading to increased permeability to gingipains, LPS, and PGN. Subsequently, gingipains become translocated to deeper epithelium for additional degradation of JAM1 and CXADR, thus allowing LPS and PGN to penetrate the gingival epithelium and reach subepithelial tissues.

transport of JAM family proteins occurs in a manner different from that of claudin and occludin.

\section{Other Cell Types}

JAM was initially identified as a platelet membrane protein [32] and shown to play an important role in platelet assembly [33]. Generally, when blood-vessel walls are damaged, platelets aggregate in the wound and serve to stop bleeding. If the function of platelets is abnormal, a bleeding tendency will develop. To monitor the health or inflammation of gingival tissues, the parameter of bleeding on probing (BOP) has been well documented $[34,35]$. Furthermore, a positive correlation between number of periodontal pockets with BOP and serum LPS concentration has been reported [36]. Thus, the molecular mechanisms related to how $P$. gingivalis affects platelets in the process of periodontal pathogenesis is quite interesting, though difficult to fully understand. Platelets are torn from the cytoplasm of polymorphonuclear giant cells in bone marrow and enter the bloodstream, and lose their nuclei. There are technical limitations when attempting to use human platelets for molecular biological research, such as passage culturing, gene manipulation, bacterial and viral contamination, and cross-contamination with the other cells, as well as confounding factors. Technical developments, including induction of differentiation to anuclear or short lifespan cells, as well as re-construction of human gingival epithelium, are needed in order to fully understand the etiology of periodontitis.

\section{AUTHOR CONTRIBUTIONS}

HT and AA wrote the manuscript. HT, EN, and SY constructed the images. All authors contributed to the article and approved the submitted version.

\section{FUNDING}

This research was supported by JSPS KAKENHI Scientific Research grants (26253094 and 18H04068) (to AA), JSPS KAKENHI Grants-in-Aid for Young Scientists (15K20360 and 17K17083) (to HT), a JSPS KAKENHI Scientific Research grant (19K10085) (to HT), and a JSPS KAKENHI Grant-in-Aid for Young Scientists (Start-up) (21K21038) (to EN), each from the Japan Society for the Promotion of Science. The funders had no role in study design, data collection, preparation of the manuscript, or decision to publish.

\section{ACKNOWLEDGMENTS}

We appreciate the technical support related to confocal laser microscopy provided by the Center for Oral Science, Osaka University Graduate School of Dentistry. We also appreciate Harumi Aoki for editing the application form for this clinical study. 


\section{REFERENCES}

1. Belibasakis GN, Kast JI, Thurnheer T, Akdis CA, Bostanci N. The expression of gingival epithelial junctions in response to subgingival biofilms. Virulence. (2015) 6:704-9. doi: 10.1080/21505594.2015. 1081731

2. Liang TW, DeMarco RA, Mrsny RJ, Gurney A, Gray A, Hooley J, et al. Characterization of huJAM1: evidence for involvement in cell-cell contact and tight junction regulation. Am J Physiol Cell Physiol. (2000) 279:C173343. doi: 10.1152/ajpcell.2000.279.6.C1733

3. Lamont RJ, Koo $\mathrm{H}$, Hajishengallis $\mathrm{G}$. The oral microbiota: dynamic communities and host interactions. Nat Rev Microl. (2018) 16:74559. doi: 10.1038/s41579-018-0089-x

4. Amano A, Kuboniwa M, Nakagawa S, Akiyama S, Morisaki I, Hamada S. Prevalence of specific genotypes of Porphyromonas gingivalis fimA and periodontal health status. J Dent Res. (2000) 79:1664-8. doi: 10.1177/00220345000790090501

5. van Winkelhoff AJ, Loos BG, van der Reijden WA, van der Velden U. Porphyromonas gingivalis, Bacteroides forsythus and other putative periodontal pathogens in subjects with and without periodontal destruction. J Clin Periodontol. (2002) 29:1023-8. doi: 10.1034/j.1600-051X.2002. 291107.x

6. Torrungruang K, Jitpakdeebordin S, Charatkulangkun O, Gleebbua Y. Porphyromonas gingivalis, Aggregatibacter actinomycetemcomitans, and Treponema denticola / Prevotella intermedia co-infection are associated with severe periodontitis in a Thai population. PLoS ONE. (2015) 10:e0136646. doi: 10.1371/journal.pone.0136646

7. Socransky SS, Haffajee AD, Cugini MA, Smith C, Kent Jr RL. Microbial complexes in subgingival plaque. J Clin Periodontol. (1998) 25:12444. doi: 10.1111/j.1600-051X.1998.tb02419.x

8. Chigasaki O, Aoyama N, Sasaki Y, Takeuchi Y, Mizutani K, Ikeda Y, et al. Porphyromonas gingivalis, the most influential pathogen in red-complex bacteria: a cross-sectional study on the relationship between bacterial count and clinical periodontal status in Japan. J Periodontol. (2021) 92:171929. doi: 10.1002/JPER.21-0011

9. Balls M. The origins and early days of the three Rs concept. Altern Lab Anim. (2009) 37:255-65. doi: 10.1177/026119290903700306

10. Nishiguchi A, Yoshida H, Matsusaki M, Akashi M. Rapid construction of three-dimensional multilayered tissues with endothelial tube networks by the cell-accumulation technique. Adv Biomater. (2011) 23:3506-10. doi: 10.1002/adma.201101787

11. Takeuchi H, Sasaki N, Yamaga S, Kuboniwa M, Matsusaki M, Amano A. Porphyromonas gingivalis induces penetration of lipopolysaccharide and peptidoglycan through the gingival epithelium via degradation of junctional adhesion molecule 1. PLoS Pathog. (2019) 15:e1008124. doi: 10.1371/journal.ppat.1008124

12. Takeuchi H, Yamaga S, Sasaki N, Kuboniwa M, Matsusaki M, Amano A. Porphyromonas gingivalis induces penetration of lipopolysaccharide and peptidoglycan through the gingival epithelium via degradation of coxsackievirus and adenovirus receptor. Cell Microbiol. (2021) 23:e13388. doi: $10.1111 / \mathrm{cmi} .13388$

13. Nakayama K, Kadowaki T, Okamoto K, Yamamoto K. Construction and characterization of arginine-specific cysteine protease (Arg-gingipain)deficient mutants of Porphyromonas gingivalis. J Biol Chem. (1995) 270:2361926. doi: 10.1074/jbc.270.40.23619

14. Potempa J, Pike R, Travis J. The multiple forms of trypsin-like activity present in various strains of Porphyromonas gingivalis are due to the presence of either Arg-gingipain or Lys-gingipain. Infect Immun. (1995) 63:117682. doi: 10.1128/iai.63.4.1176-1182.1995

15. Murakami S, Yoshimura N, Koide H, Watanabe J, Takedachi M, Terakura M, et al. Activation of adenosine receptor-enhanced iNOS mRNA expression by gingival epithelial cells. J Dent Res. (2004) 81:236-40. doi: 10.1177/154405910208100403

16. Shi Y, Ratnayake DB, Okamoto K, Abe N, Yamamoto K, Nakayama K. Genetic analysis of proteolysis, hemoglobin binding, and hemagglutination of Porphyromonas gingivalis. Construction of mutants with a combination of rgpA, rgpB, kgp, and hagA. J Biol Chem. (1999) 274:17955-60. doi: 10.1074/jbc.274.25.17955
17. Ebnet K, Suzuki A, Ohno S, Vestweber D. Junctional adhesion molecules (JAMs): more molecules with dual functions? J Cell Sci. (2004) 117:1929. doi: $10.1242 /$ jcs. 00930

18. Weber C, Fraemohs L, Dejana E. The role of junctional adhesion molecules in vascular inflammation. Nat Rev Immunol. (2007) 7:46777. doi: 10.1038/nri2096

19. Kolenbrander PE, Anderson RN, Blehert DS, Egland PG, Foster JS, Palmer RJ Jr. Communication among oral bacteria. Microbiol Mol Biol Rev. (2002) 66:486-505. doi: 10.1128/MMBR.66.3.486-505.2002

20. Kawai T, Akira S. Toll-like receptors and their crosstalk with other innate reeptors in infection and immunity. Immunity. (2011) 34:63750. doi: 10.1016/j.immuni.2011.05.006

21. Albander JM, Susin C, Hughes FJ. Manifestations of systemic diseases and conditions that affect the periodontal attachment apparatus: Case definitions and diagnostic considerations. J Periodontol. (2018) 89(Suppl 1): S183203. doi: 10.1002/JPER.16-0480

22. Moutsopoulos NM, Chalmers NI, Barb JJ, Abusleme L, Greenwell-Wild $\mathrm{T}$, Dutzan N, et al. Subgingival microbial communities in leukocyte adhesion deficiency and their relationship with local immunopathology. PLoS Pathog. (2015) 11:e1004698. doi: 10.1371/journal.ppat. 1004698

23. Shaddox LM, Wiedey J, Calderon NL, Magnusson I, Bimstein E, Bidwell JA, et al. Local inflammatory markers and systemic endotoxin in aggressive periodontitis. J Dent Res. (2011) 90:1140-4. doi: 10.1177/0022034511 413928

24. Kalash D, Vovk A, Huang H, Aukhil I, Wallet SM, Shaddox LM. Influence of periodontal therapy on systemic lipopolysaccharides in children with localized aggressive periodontitis. Pediatr Dent. (2015) 37:35-40.

25. Fan S, Weight CM, Lussint AC, Hilgarth RS, Brazil JC, Ettel M, et al. Role of JAM-A tyrosine phosphorylation in epithelial barrier dysfunction during intestinal inflammation. Mol Biol Cell. (2019) 30:56678. doi: 10.1091/mbc.E18-08-0531

26. Ozaki H, Ishii K, Arai H, Horiuchi H, Kawamoto T, Suzuki H, et al. Junctional adhesion molecule (JAM) is phosphorylated by protein kinase C upon platelet activation. Biochem Biophys Res Commun. (2000) 276:8738. doi: 10.1006/bbrc.2000.3574

27. Scott DW, Tolbert CE, Graham DM, Wittchen E, Bear JE, Burridge $\mathrm{K}$. N-glycosylation controls the function of junctional adhesion molecule-A. Mol Biol Cell. (2015) 26:3205-14. doi: 10.1091/mbc.e1412-1604

28. Excoffon KJ, Gansemer N, Traver G, Zebner J. Functional effects of coxsackievirus and adenovirus receptor glycosylation on homophilic adhesion and adenoviral infection. J Virol. (2007) 81:5573-8. doi: 10.1128/JVI. 02562-06

29. Songyang Z, Fanning AS, Fu C, Xu J, Marfatia SM, Chishti AH, et al., Recognition of unique carboxyl-terminal motifs by distinct PDZ domains. Science. (1997) 275:73-7. doi: 10.1126/science.275.5296.73

30. Steinbacher T, Kummer D, Ebnet K. Junctional adhesion molecule-A: functional diversity through molecular promiscuity. Cell Mol Life Sci. (2018) 75:1393-409. doi: 10.1007/s00018-017-2729-0

31. Shen L, Turner JR. Actin depolymerization disrupts tight junctions via caveolae-mediated endocytosis. Mol Biol Cell. (2005) 16:3919-36. doi: 10.1091/mbc.e04-12-1089

32. Kornecki E, Walkowiak B, Naik UP, Ehrlich YH. Activation of human platelets by a stimulatory monoclonal antibody. J Biol Chem. (1990) 265:100428. doi: 10.1016/S0021-9258(19)38776-9

33. Sobocka MB, Sobocki T, Banerjee P, Weiss C, Rushbrook JI, Norin AJ, et al. Cloning of the human platelet F11 receptor: a cell adhesion molecule member of the immunoglobulin superfamily involved in platelet aggregation. Blood. (2000) 95:2600-9. doi: 10.1182/blood.V95. 8.2600

34. Lang NP, Joss A, Tonetti MS. Monitoring disease during supportive periodontal treatment by bleeding on probing. Periodontol 2000. (1996) 12:44-8. doi: 10.1111/j.1600-0757.1996.tb00080.x

35. Lang NP, Bartold PM. Periodontal health. J Periodontol. (2018) 89(Suppl 1):S9-16. doi: 10.1002/JPER.16-0517

36. Pussinen PJ, Vilkuna-Rautiainen T, Alfthan G, Palosuo T, Jauhiainen M, Sundvall J, et al. Severe periodontitis enhances macrophage activation via 
increased serum lipopolysaccharide. Arterioscler Thromb Vasc Biol. (2004) 24:2174-80. doi: 10.1161/01.ATV.0000145979.82184.9f

Conflict of Interest: The authors declare that the research was conducted in the absence of any commercial or financial relationships that could be construed as a potential conflict of interest.

Publisher's Note: All claims expressed in this article are solely those of the authors and do not necessarily represent those of their affiliated organizations, or those of the publisher, the editors and the reviewers. Any product that may be evaluated in this article, or claim that may be made by its manufacturer, is not guaranteed or endorsed by the publisher.

Copyright $\odot 2022$ Takeuchi, Nakamura, Yamaga and Amano. This is an open-access article distributed under the terms of the Creative Commons Attribution License (CC $B Y)$. The use, distribution or reproduction in other forums is permitted, provided the original author(s) and the copyright owner(s) are credited and that the original publication in this journal is cited, in accordance with accepted academic practice. No use, distribution or reproduction is permitted which does not comply with these terms. 